\title{
Acceleration of the Inflammatory Response of the Renal Medulla by Water Diuresis *
}

\author{
Vincent T. Andriole $\dagger$ \\ (From the Department of Internal Medicine, Yale University School of Medicine, Nerw Haven, \\ and the Veterans Administration Hospital, West Haven, Conn.)
}

The habitual hypertonicity of the renal medulla appears to be an important determinant of the unique vulnerability of this tissue to infection $(1,2)$. Experimental pyelonephritis can be prevented, in the rat, by decreasing the normally hypertonic environment of the renal medulla through sustained water diuresis (1). However, the precise mechanism responsible for the protection afforded the renal medulla during water diuresis has not been clearly defined.

The rapidity of leukocyte mobilization to the site of primary lodgment of bacteria has been shown to be important in determining, at least in part, the fate of invading microbial agents (36). A delay in the mobilization of granulocytes has been observed in the medulla of the rabbit kidney after acute thermal injury (7), which suggests that deficiencies in granulocyte mobilization play an important role in the increased susceptibility of the renal medulla to bacterial infection. It seemed desirable to determine the effect of water diuresis on the mobilization of leukocytes into the medulla of the kidney insofar as this might explain the decreased susceptibility of the kidney to infection during water diuresis. Thermal injury was selected to initiate an inflammatory response specifically to avoid the effects of bacterial infection on leukocyte integrity. The results of the present studies indicate a marked difference in the speed of leukocyte mobilization into the renal medulla of control rats as compared with the renal medulla of animals undergoing water diuresis.

* Submitted for publication December 9, 1965 ; accepted February 17, 1966.

Aided by grants AI 05585 and AI 06308 from the U. S. Public Health Service and by a grant from the American Heart Association.

$\dagger$ Recipient of an Established Investigatorship of the American Heart Association. Address requests for reprints to Dr. Vincent T. Andriole, Dept. of Internal Medicine, Yale University School of Medicine, 333 Cedar St., New Haven, Conn.

\section{Methods}

Animals. White male Sprague-Dawley strain rats weighing 200 to $300 \mathrm{~g}$ were used. All animals were fed Purina lab chow pellets and tap water ad libitum.

Water diuresis. Chronic water diuresis was induced in rats as previously reported (1), by adding $5 \%$ glucose to their drinking water. The daily volume of fluid intake and urine output was measured for each rat. Urine samples were analyzed for glucose with Clinitest reagent and for osmolality with a Fiske osmometer.

Thermal injury. Animals were anesthetized by the intraperitoneal administration of the sodium salt of 5-ethyl-5-(1-methylpropyl)-thiobarbituric acid (inactin) in sterile distilled water in a dose of $80 \mathrm{mg}$ per $\mathrm{kg}$ of body weight. This anesthetic was chosen because, unlike ether or pentobarbital, it does not interrupt water diuresis in rats. The left kidney was selected for injury, and sterile technique was maintained during all surgical procedures. After removal of the hair with an electric clipper, the operative site was cleansed with $70 \%$ alcohol. A $2.5-\mathrm{cm}$ left flank skin incision was made, and the left kidney was delivered into the operative wound. Thermal injury was produced with a fine electrocautery wire, insulated except for the distal $2 \mathrm{~mm}$ and attached to one of the electrodes of a Radiosurg scalpel machine (model S-1). Cortical burns were made on the lateral aspect of the kidney by introducing the wire into the parenchyma to a depth of $2 \mathrm{~mm}$. Medullary burns were produced by inserting the cautery wire into the anterior surface of the kidney $6 \mathrm{~mm}$ from the lateral margin, midway between the upper and lower poles, to a depth of $4 \mathrm{~mm}$. The current was applied for approximately 1 second. After production of one or more areas of cortical injury and only one medullary injury per kidney, the wound was closed with silk sutures and skin clips. A polyethylene tube was inserted through the mouth, into the stomach of control rats and of rats undergoing diuresis, after the onset of anesthesia. Fluid was administered by continuous drip through the gastric tubes throughout the period of narcosis in volumes of 3 to $5 \mathrm{ml}$ of $5 \%$ glucose and water or $1 \mathrm{ml}$ of tap water per hour to rats undergoing diuresis and control animals, respectively, in order that the preoperative fluid intake and urinary output in each group might be continued without interruption.

Kidneys were removed at 4, 8, 12, and 24 hours after thermal injury, fixed in $10 \%$ formalin, and serially sectioned. Every fifth section was mounted, stained with 
hematoxylin-eosin, and studied microscopically. A minimum of 50 , and more often 75 to 90 , sections from at least 8 cortical and 4 medullary lesions were studied in each category.

The inflammatory response of each lesion was evaluated and recorded as follows: no granulocytic infiltrate, occasional granulocyte, diffuse granulocytic infiltrate, focal clumps of granulocytes, and dense granulocytic infiltrate. Leukocyte margination, cellular infiltration, edema, and necrosis were also estimated in each lesion.

\section{Results}

Comparison of the acute inflammatory response in the renal medulla of control rats and those undergoing water diuresis (Figure 1). Examination of all kidneys studied confirmed that the thermal injury had been placed in either the inner medulla or papilla of the kidney. Cellular infiltrate, when present, was predominantly granulocytic and occurred at the periphery of the burn. In contrast, the center of each burn was uniformly avascular and necrotic. Hemorrhage, congestion, edema, and necrosis appeared comparable in medullary lesions of kidneys from both control animals and those undergoing diuresis. Although attempts were made to grade each lesion quantitatively, definitive granulocyte infiltration was considered to be present when a diffuse leukocytic infiltrate, focal clumps of leukocytes, or dense leukocytic infiltrate was observed. Lesions containing an occasional granulocyte, although recorded, were considered as having no appreciable inflammatory response.

Leukocytes were not seen in the medullary lesions of control animals studied 4 hours after thermal injury. In contrast, half of the corresponding medullary lesions in animals undergoing diuresis contained a slight but diffuse granulocytic infiltrate at the periphery of the burn. The remaining half of the medullary lesions of animals undergoing diuresis contained an occasional granulocyte also seen at the peripheral areas of the burn. Although these observations suggested that the mobilization of leukocytes into the renal medulla of animals undergoing a water diuresis was enhanced as early as 4 hours after injury, the differences observed were not striking.

Eight hours after thermal injury there were still no leukocytes seen in the medullary burn of
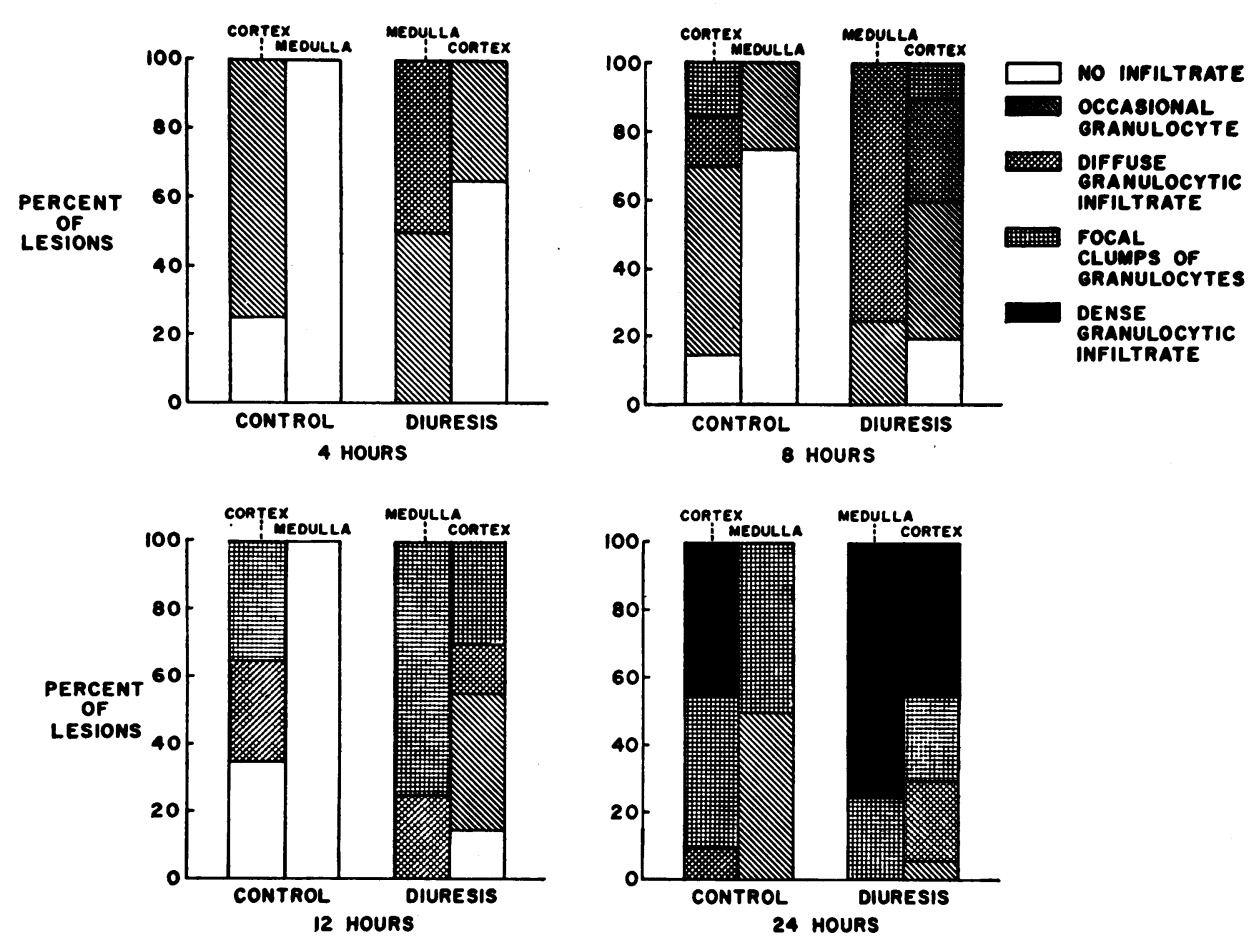

Fig. 1. Comparison of the inflammatory REsPonse in the cortex AND Medulla of CONTROL RATS AND RATS UNDERGOING A WATER DIURESIS 4, 8, 12, AND 24 HOURS AFTER THERMAL INJURY. 


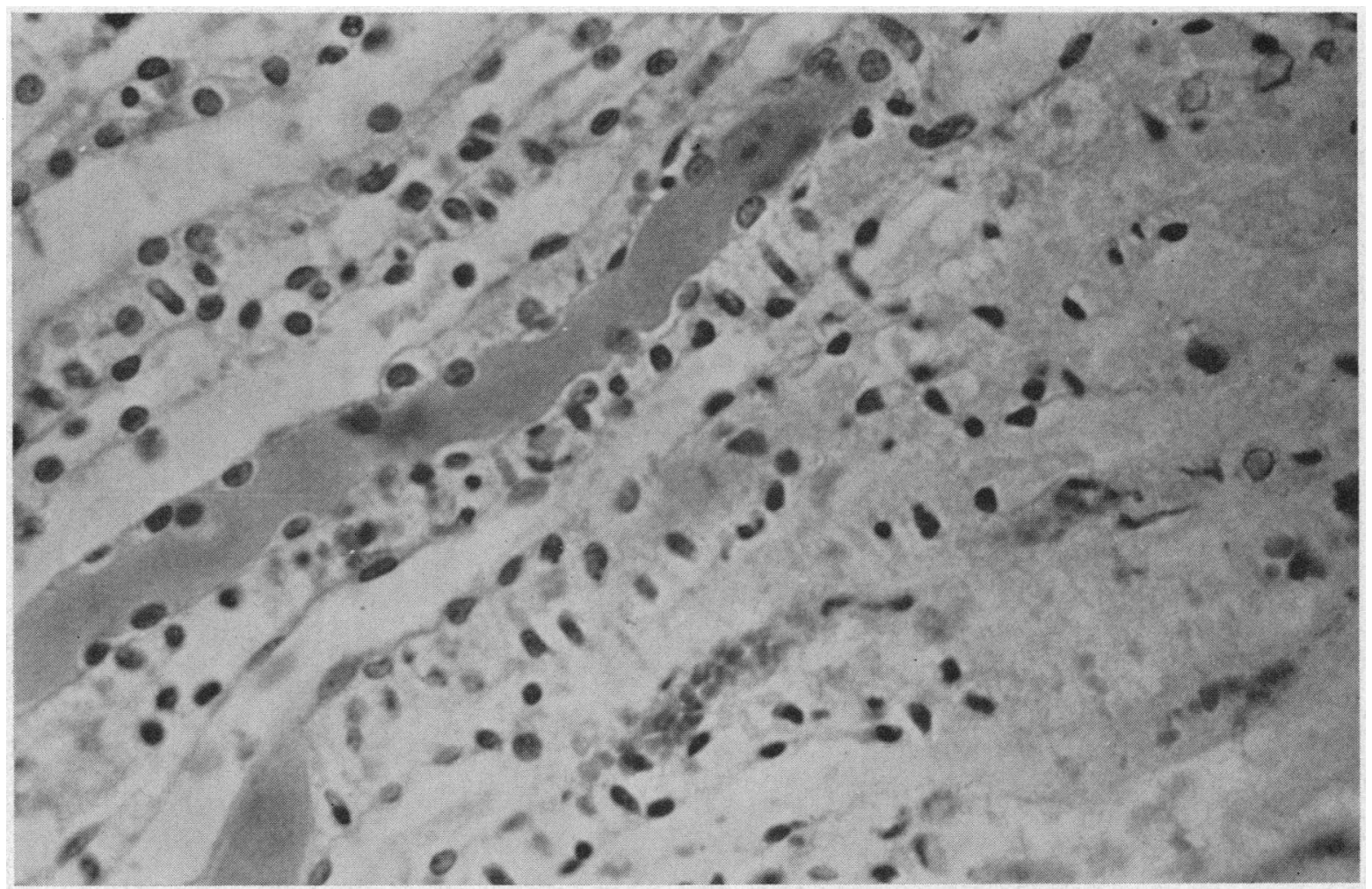

Fig. 2. MARGin OF MEDULlary BURN IN CONTROL RATS, 8 HOURS. The relative absence of granulocytes represents the typical response observed in the medulla of control rats 4,8 , and 12 hours after injury. Hematoxylin and eosin. $\times 400$.

control animals (Figure 2) except for an occasional granulocyte observed in the peripheral area of one lesion. In contrast, $75 \%$ of medullary lesions in animals undergoing diuresis clearly contained a diffuse peritubular and intratubular granulocytic infiltrate at the periphery of the burn (Figure 3).

Twelve hours after thermal injury leukocytes were still not readily seen in medullary lesions of control animals. However, numerous granulocytes, largely in focal clumps, were observed in the peripheral areas of medullary lesions of kidneys from rats undergoing water diuresis (Figure 4).

The first inflammatory response to thermal injury in the medulla of control animals was observed in tissue sections obtained 24 hours after burn and was similar in intensity to the inflammatory response observed in kidneys undergoing diuresis at 8 and 12 hours. In comparison, the inflammatory response observed in medullary lesions of animals undergoing diuresis 24 hours after burn was greater than similar lesions in con- trol rats and consisted of a dense, peritubular and intratubular granulocytic infiltration with occasional mononuclear cells (Figure 5).

Comparison of the acute inflammatory response in the cortex of control kidneys and of those undergoing diuresis (Figure 1). The inflammatory response after thermal injury to the renal cortex of control rats and those undergoing diuresis was not so uniform as that observed in the medulla. No infiltrate could be seen in some cortical burns as late as 12 hours after injury in both control animals and rats undergoing diuresis. In other instances, a clear-cut inflammatory response was seen as early as 8 hours. In early lesions, granulocytic infiltration into the cortex, when present, was peritubular or periglomerular and occurred at the periphery of the burn area. In contrast, focal clumps of granulocytes or dense granulocytic infiltration, seen predominantly in later lesions, occurred in the center of the burn rather than at its periphery. The granulocytic infiltrate encircling cortical burns 12 and 24 hours after in- 


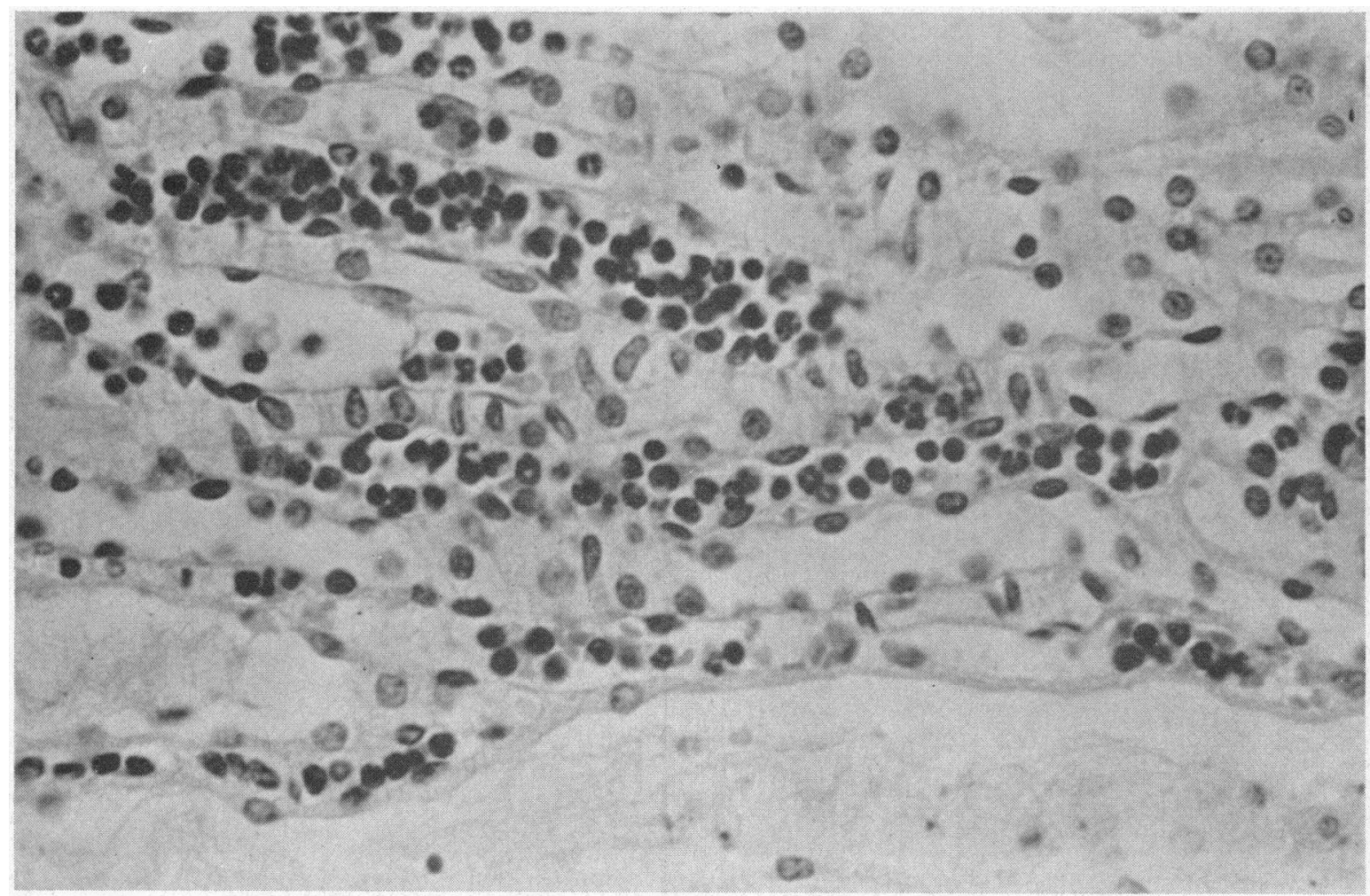

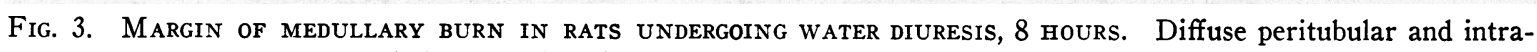
tubular granulocytic infiltrate. Hematoxylin and eosin. $\times 400$.

jury, which has been observed in the rabbit kidney (7), was not seen in the present studies. Although glomerular hemorrhage, edema, congestion, and necrosis were observed at all intervals studied and were comparable in cortical burns from both control animals and animals undergoing diuresis, leukocytic infiltration into glomeruli was never observed.

The first good cortical inflammatory response, seen in those lesions studied 8 hours after thermal injury, appeared to progress in intensity by 12 and again by 24 hours regardless of whether the lesions were produced in the cortex of control rats or animals undergoing diuresis. Although the response to lesions in both groups was variable, there seemed to be no difference between the average inflammatory reaction observed in the renal cortex of control rats and the cortex of animals undergoing diuresis when lesions were compared at the same interval after thermal injury.

Comparison of acute inflammatory responses in the cortex with those in the medulla of control kidneys and those undergoing water diuresis (Fig- ure 1). The granulocytic exudate which occurred in most cortical burns produced in control rats was greater than that which occurred in the medulla of the same kidneys at all intervals studied. Although only a minimal inflammatory response was present in most cortical burns at 4 and 8 hours after injury, a significant inflammatory exudate was observed in 30,65 , and $100 \%$ of cortical lesions at 8,12 , and 24 hours after injury, respectively. The average inflammatory response in the medulla of these same kidneys was delayed and diminished in intensity when compared with that in the cortex.

In contrast, the promptness and intensity of the average inflammatory response in the renal medulla of rats during water diuresis were equal to or greater than the inflammatory response observed in cortical lesions in the same animals.

Urinary osmolality (Figure 6). The mean osmolality of the urine before inactin anesthesia was 1,100 and $125 \mathrm{mOsm}$ per $\mathrm{kg}$ in 9 control and 11 rats undergoing diuresis, respectively, and closely approximated the values obtained in a previous 
study (1). These values remained relatively constant (4-, 8-, and 12-hour determinations) in both groups during narcosis and in animals undergoing diuresis after inactin anesthesia (24hour determinations). A slight decrease was observed in the osmolality of the urine samples obtained from control rats 24 hours after the onset of anesthesia.

Urine flow before anesthesia averaged $0.7 \mathrm{ml}$ per hour in 10 control rats and $4.0 \mathrm{ml}$ per hour in 16 rats undergoing water diuresis. Similar mean rates of urine flow, $0.7 \mathrm{ml}$ per hour in control animals and $3.0 \mathrm{ml}$ per hour in animals undergoing water diuresis, were observed during inactin anesthesia. Glucosuria did not occur in those rats undergoing water diuresis.

\section{Discussion}

The present studies demonstrate that water diuresis enhances the mobilization of granulocytes into the renal medulla as early as 4 and clearly by 8 hours after injury. In contrast, there is a delayed inflammatory response in the normally hypertonic renal medulla where granulocytes first appear between 12 and 24 hours. The present studies also demonstrate that leukocytes are mobilized into the renal cortex with equal rapidity in both control rats and animals undergoing diuresis and at a faster rate than observed in the normal renal medulla. The rapidity of granulocyte mobilization into the renal medulla during water diuresis is comparable to the speed of granulocyte mobilization into the renal cortex, normal human skin $(5,8)$, and guinea pig skin $(6,9)$, tissues that have been shown to be relatively resistant to bacterial infection. In contrast, the delayed inflammatory response in the medulla of control rats is similar to the delay in leukocyte mobilization seen in the medulla of normal rabbit kidneys (7), the skin of untreated leukemic patients (8), and alloxan-diabetic acidotic rabbits (4), which appears to explain, at least in part, the increased susceptibility of these tissues to bacterial infection.

Blood and interstitial fluids of the medulla are hypertonic when the urine is concentrated, but ap-

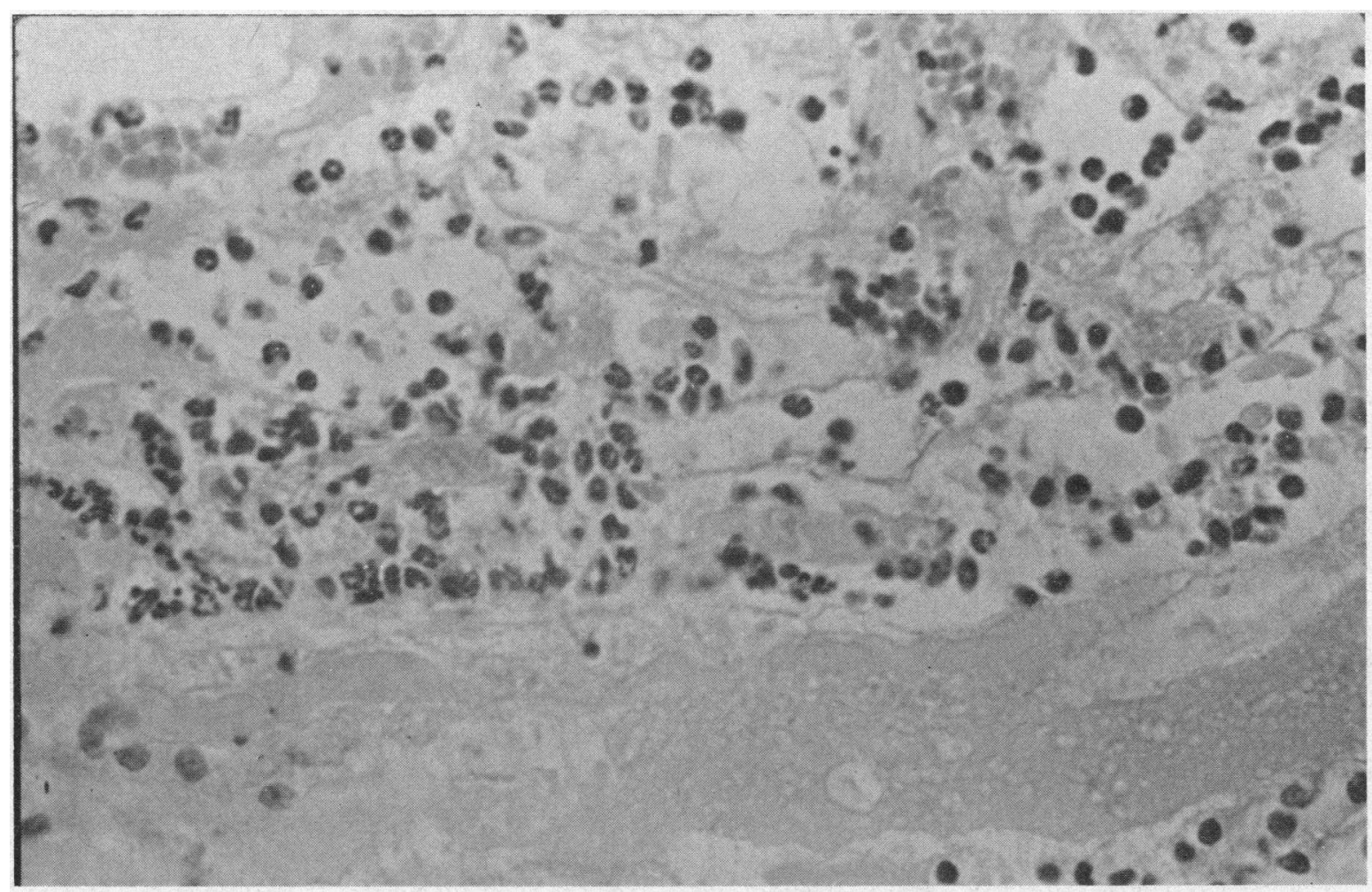

Fig. 4. MARgin of MEdullary bURN IN RATS UNDERgoing Water diUREsis, 12 hours. Fócal granulocytic infiltrate. Hematoxylin and eosin. $\times 400$. 


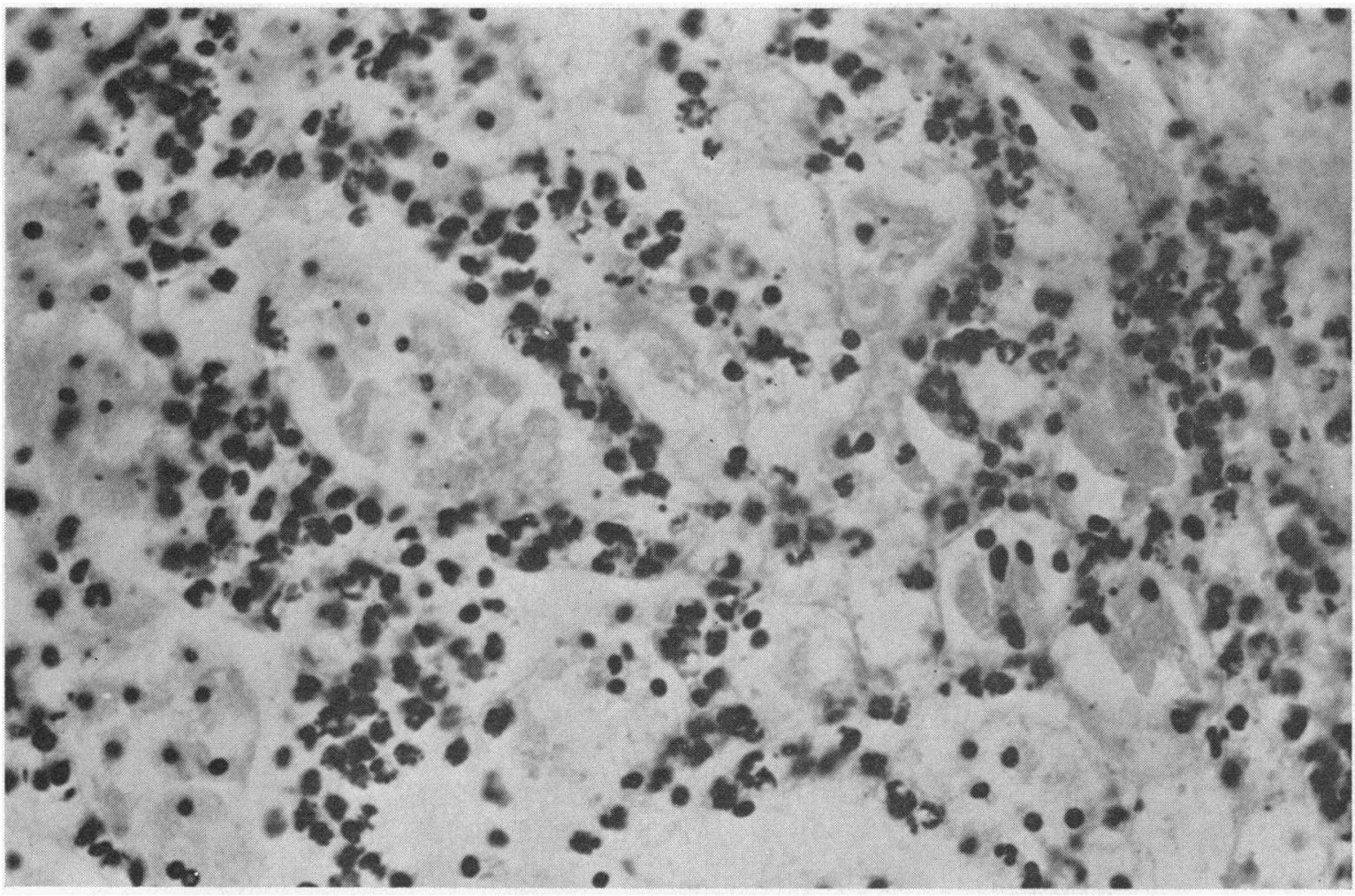

Fig. 5. Margin of Medullary bURn in Rats Undergoing water diUResis, 24 hours. Dense peritubular and intratubular granulocytic infiltrate. Hematoxylin and eosin. $\times 400$.

proach the tonicity of peripheral blood during water diuresis $(1,10)$. The present data, therefore, suggest that an isotonic or nearly isotonic environment may be necessary for prompt leukocyte migration, since water diuresis, which accelerated the inflammatory response, is known to decrease the concentration of solutes in the normally hypertonic tissues of the renal medulla (1). In addition to changes in the tonicity of the medulla, changes in blood flow to the medulla may be related to the enhanced mobilization of leukocytes in this tissue during water diuresis. Since water diuresis probably increases blood flow to the medulla (but not the cortex $)(10,11)$, the enhanced inflammatory response observed in the medulla (but not the cortex) during water diuresis might simply result from the more rapid delivery of greater numbers of phagocytes to the area of injury. The influences of medullary osmolality and of medullary blood flow upon susceptibility to infection are difficult to separate. Hamburger (12) and Chernew and Braude (2) have demonstrated that hypertonic environments, within the range normally found in the renal medulla, inhibit phagocytosis by polymorphonuclear leukocytes, and the present data suggest that hypertonicity may also delay the migration of polymorphonuclear leukocytes to the site of injury.

Previous observations by many workers (3-9) have suggested that the rapidity of granulocyte mobilization is a major determinant of the eventual outcome between microbe and host after primary lodgment of the organism, and the observations of Rocha and Fekety (7) in particular suggest that deficiencies in granulocyte mobilization play an important role in the increased susceptibility of the renal medulla to infection. In addition, Louria, Fallon, and Browne (13) and Rocha and Fekety ( 7 ) have suggested that intratubular residence of bacteria and fungi in the renal medulla may provide some protection from destruction by cellular defense mechanisms. The absence of intratubular granulocytes in the medulla of control rat kidneys examined in the present studies and in the kidneys of rabbits observed by Rocha and Fekety (7) supports this concept. Furthermore, 
the present data clearly demonstrate that granulocytes are not only present in the renal medulla shortly after injury, but they are also frequently found in the lumen of those medullary tubules around the injured area in rats undergoing water diuresis. These observations, therefore, may possibly explain, at least in part, the protective effect of water diuresis in preventing renal infection (1). Although water diuresis enhances the mobilization of leukocytes into the medulla, other mechanisms of resistance may also be affected by this procedure. Water diuresis, simply by increasing medullary blood flow, may also enhance the delivery of antibody, complement, or other bactericidal elements of blood to the injured medulla. However, no attempt was made to define these possibilities in the present study.

Water diuresis clearly decreases medullary hypertonicity (1), permits a prompt granulocytic response to medullary injury, and provides a favorable environment for phagocytosis per se (2). In these respects, therefore, experimental support is provided for the well-established clinical practice of "forcing fluids" in patients with renal infection.

\section{Summary}

The acute inflammatory response to thermal injury in the medulla and cortex of control rats and rats undergoing a chronic water diuresis was determined by serial histologic study. Water diuresis enhanced the mobilization of granulocytes into the renal medulla. In contrast, the inflammatory response was delayed and diminished in intensity in the renal medulla of rats excreting a concentrated urine. Leukocytes were mobilized into the renal cortex with equal rapidity in both control animals and animals undergoing diuresis and at a faster rate than that observed in the renal medulla of control animals.

These results suggest that an isotonic or nearly isotonic environment may be necessary for prompt leukocyte migration into the medulla of the kidney and that the speed of granulocyte mobilization may have some bearing on the protective effect of water diuresis in preventing renal infection.

\section{Acknowledgment}

The technical assistance of Cynthia B. Lambert is most gratefully appreciated.

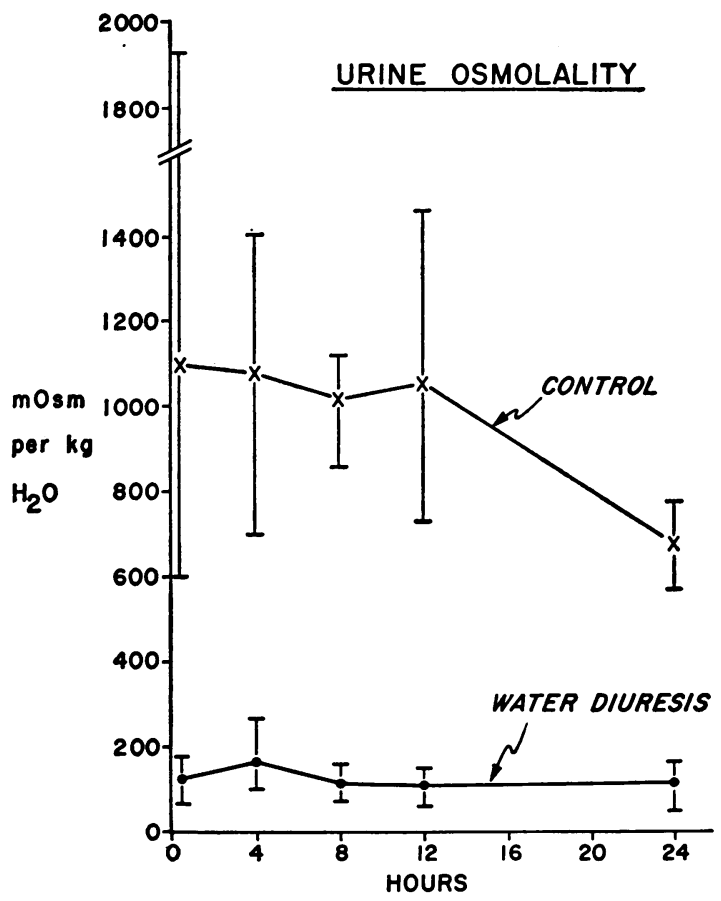

Fig. 6. URINE OSMOLALITY, MEAN AND RANGE OF VALUES, BEFORE ( 0 HOURS) AND DURING $(4,8,12$, AND 24 HOURS) INACTIN ANESTHESIA IN 9 CONTROL RATS AND 11 RATS UNDERGOING WATER DIURESIS.

\section{References}

1. Andriole, V. T., and F. H. Epstein. Prevention of pyelonephritis by water diuresis: evidence for the role of medullary hypertonicity in promoting renal infection. J. clin. Invest. 1965, 44, 73.

2. Chernew, I., and A. I. Braude. Depression of phagocytosis by solutes in concentrations found in the kidney and urine. J. clin. Invest. 1962, 41, 1945.

3. Miles, A. A., E. M. Miles, and J. Burke. The value and duration of defense reactions of the skin to the primary lodgement of bacteria. Brit. J. exp. Path. 1957, 38, 79.

4. Sheldon, W. H., and H. Bauer. The development of the acute inflammatory response to experimental cutaneous mucormycosis in normal and diabetic rabbits. J. exp. Med. 1959, 110, 845.

5. Perillie, P. E., and S. C. Finch. The local exudative cellular response in leukemia. J. clin. Invest. 1960, 38, 1353.

6. Andriole, V. T., and B. Lytton. The effect and critical duration of increased tissue pressure on susceptibility to bacterial infection. Brit. J. exp. Path. 1965, 46, 308.

7. Rocha, H., and F. R. Fekety, Jr. Acute inflammation in the renal cortex and medulla following thermal injury. J. exp. Med. 1964, 119, 131. 
8. Perillie, P. E., and S. C. Finch. Quantitative studies of local exudative cellular reaction in acute leukemia. J. clin. Invest. 1964, 43, 425.

9. Miles, A. A., and J. S. F. Niven. The enhancement of infection during shock produced by bacterial toxins and other agents. Brit. J. exp. Path. 1950, $31,73$.

10. Ullrich, K. J., K. Kramer, and J. W. Boylan. Present knowledge of the counter-current system in the mammalian kidney. Progr. cardiovasc. Dis. 1961, 3, 395.
11. Thurau, K., P. Deetjen, and K. Kramer. Hämodynamik des Nierenmarks. II. Mitteilung. Wechselbeziehung zwischen vasculärem und tubulärem Gegenstromsystem bei arteriellen Drucksteigerungen, Wasserdiureses und osmotischer Diureses. Pflügers Arch. ges. Physiol. 1960, 270, 270.

12. Hamburger, H. J. Physikalisch-chemisch Untersuchungen über Phagozyten. Wiesbaden, 1912.

13. Louria, D. B., N. Fallon, and H. G. Browne. The influence of cortisone on experimental fungus infections in mice. J. clin. Invest. 1960, 39, 1435.

\section{SPECIAL NOTICE TO SUBSCRIBERS}

Post Offices will no longer forward the Journal when you move.

Please notify The Journal of Clinical Investigation, Business Office, 10 Stoughton Street, Boston, Mass. 02118, at once when you have a change of address, and do not omit the Zip Code number. 